\title{
Hepatitis $C$ virus infection and the risk of intrahepatic cholangiocarcinoma and extrahepatic cholangiocarcinoma: evidence from a systematic review and meta-analysis of 16 case-control studies
}

Hao $\mathrm{Li}^{1+}$, Bin $\mathrm{Hu}^{1 \dagger}$, Zun-Qiang Zhou' ${ }^{2}$ Jiao Guan², Zheng-Yun Zhang ${ }^{2^{*}}$ and Guang-Wen Zhou ${ }^{2^{*}}$

\begin{abstract}
Background: Studies investigating the association between hepatitis $\mathrm{C}$ virus (HCV) infections and the occurrence of cholangiocarcinoma (CCA), especially intrahepatic cholangiocarcinoma (ICC), have shown inconsistent findings. Although previous meta-analyses referred to HCV and CCA, they mainly focused on ICC rather than CCA or extrahepatic cholangiocarcinoma (ECC). Since then, relevant new studies have been published on the association between HCV and ICC. Since the different anatomic locations of CCA have distinct epidemiologic features and different risk factors, it is necessary to evaluate the relationship between HCV infection and ICC, ECC, and CCA.

Methods: Relevant studies were identified by searching PUBMED, EMBASE, and MEDLINE databases prior to 1 August 2013. Pooled risk estimates were calculated with random-effects models using STATA 11.0.

Results: A total of 16 case-control studies were included in the final analysis. Pooled risk estimates showed a statistically significant increasing risk of CCA (odds ratio $(\mathrm{OR})=5.44,95 \% \mathrm{Cl}, 2.72$ to 10.89). The pooled risk estimate of ICC (OR $=3.38$, $95 \% \mathrm{Cl}, 2.72$ to 4.21$)$ was higher than that of ECC (OR $=1.75,95 \% \mathrm{Cl}, 1.00$ to 3.05). In a subgroup analysis, the pooled risk estimate of ICC in studies from North America was obviously higher than in Asia (6.48 versus 2.01). The Begg funnel plot and Egger test showed no evidence of publication bias.
\end{abstract}

Conclusions: HCV infection is associated with the increasing risk of CCA, especially ICC.

Keywords: HCV, Intrahepatic cholangiocarcinoma, Extrahepatic cholangiocarcinoma, Risk factor, Meta-analysis

\section{Background}

Cholangiocarcinoma (CCA) is a malignant neoplasm arising from the epithelial cells of the intrahepatic or extrahepatic bile ducts. Therefore, CCA can be classified as intrahepatic cholangiocarcinoma (ICC) and extrahepatic cholangiocarcinoma (ECC). CCA is the second most common primary hepatic malignancy, representing $10 \%$ to $25 \%$ of primary hepatic malignancies worldwide, accounting for $3 \%$ of all gastrointestinal tumors [1-3]. It

\footnotetext{
* Correspondence: zhengyunzh@yahoo.com.cn; gwzhousfph@163.com ${ }^{\dagger}$ Equal contributors

${ }^{2}$ Department of Surgery, Shanghai Jiao Tong University Affiliated Sixth People's Hospital, No. 600, Yishan Road, 200233 Shanghai, China Full list of author information is available at the end of the article
}

has been shown that CCA is characterized by a low survival rate, with a median survival of less than 24 months [4].

Defining the risk factors for CCA benefits the search for better ways to prevent the occurrence of this disease. To date, it has been shown that hepatolithiasis, primary sclerosing cholangitis, liver flukes, biliary duct cysts, specific toxins (for example, the carcinogenic agent thorotrast), inflammatory bowel disease, and genetic polymorphisms are the major risk factors for CCA [5-8]. Although the association between CCA and viral hepatitis infections has been examined in several studies, the results remain controversial, especially for the hepatitis C virus (HCV) [7,9-15]. Several case-control studies have suggested that HCV infection plays a major role in CCA development [9-14]. In

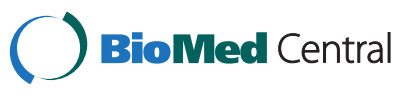


contrast, other studies have revealed no significant associations between CCA and HCV $[7,15]$. Therefore, in the present study, we performed a systematic review and metaanalysis to better evaluate the risk of CCA development in $\mathrm{HCV}$-infected patients.

\section{Methods}

Literature search

Two independent reviewers searched PUBMED, EMBASE, and MEDLINE databases prior to 1 August 2013. The $\mathrm{MeSH}$ (Medical Subject Heading) search included headings that were all combinations of the hepatitis $\mathrm{C}$ virus such as: $\mathrm{HCV}$, cholangiocarcinoma, intrahepatic, extrahepatic, bile duct cancer, and bile duct neoplasm. We also reviewed the reference lists of retrieved articles to search for more relevant studies. There were no language restrictions.

\section{Inclusion and exclusion criteria}

Studies were eligible if they met the following criteria: (1) case-control studies; (2) exposure to HCV infection; (3) the outcome was CCA, ICC, or ECC incidence; and (4) providing risk estimates with $95 \%$ confidence interval (CI) or available information to calculate them. Abstracts, letters, reviews, case reports, studies lacking control groups, and studies that did not provide sufficient data to calculate risk estimates were excluded. Two investigators independently selected studies, and any discrepancies were resolved by consensus.

\section{Data extraction}

For each eligible study, the following parameters were extracted independently by two researchers: (1) first author's last name, date of study publication and the country where the study was conducted; (2) study design; (3) type of control; (4) sample size and age; (5) number of exposure in cases and controls; (6) risk estimate and 95\% CI; and (7) adjustments and other information. The present meta-analysis included different measures of risk estimates (odds ratio, incidence rate ratio, standardized incidence ratio, and hazard ratio). In fact, the different measures yielded a similar risk estimate due to the relatively scarce occurrence of cholangiocarcinoma.

\section{Statistical analysis}

A pooled risk estimate was calculated with a randomeffects model, considering both intra-study and interstudy variances. Statistical heterogeneity was evaluated using the $Q$ and $I^{2}$ statistics. For the $Q$ statistic, $P<0.10$ was used as an indication of the existence of heterogeneity. Subgroup analysis was performed to explore potential heterogeneity among studies. Publication bias was assessed using the Begg funnel plot and the Egger test, and a $P<0.10$ was considered as an indicator for publication bias [16,17]. All statistical analyses were conducted using STATA 11.0 for Windows (Stata, College Station, TX, USA).

\section{Results}

Search results

A total of 159 articles were identified through the literature search. Of these, 146 studies were excluded because they were either review articles, case reports, letters, or were not case-control studies. Studies were excluded when exposure was not an HCV infection and outcomes were not CCA, ICC, or ECC. The remaining 13 casecontrol studies, plus 8 studies from the reference lists, added 21 studies, of which 5 were excluded because of duplicates from the same population and risk estimates were not available. After strict screening, a total of 16 case-control studies were ultimately included in the present study [7,9-15,17-24] (Figure 1). The main features of these studies are shown in Table 1. We identified 16 case-control studies from 1991 to 2012. Four studies were from the USA [12-14,23], six from China $[7,15,18,20,22,24]$, one from Taiwan [19], two from South Korea [9,17], one from Italy [10], one from Japan [11], and one from Thailand [21]. Data of a total of 3,658 patients with ICC and 1,280 with ECC were reported in these case-control studies. One study including 103 CCA cases did not classify ICC and ECC [21]. Among 5,044 cases, data of 140 patients with HCV infection were reported, whereas among 396,887 control subjects, data of a total of 1,879 subjects with $\mathrm{HCV}$ infection were reported. The diagnosis of CCA was confirmed by pathological examination. HCV infection was confirmed by laboratory tests. Controls recruited originated from hospital-based [7,9-11,13,15,17,19-22,24] or general population-based groups $[12,14,18,23]$. Control subjects $[9-11,15,19,21]$ were selected from patients with non-liver-related cancer or other non-cancer disease and from healthy individuals at health screening centers of hospitals in four studies $[13,17,20,22]$. Qu et al. [24] selected participants with benign biliary disease with cholelithiasis or acute cholangitis as controls, whereas Liu et al. [7] selected patients with hepatolithiasis alone as controls. In 15 of the selected 16 studies, age-matched and sex-matched controls were used [7,9-15,17,19-24]. One study had two control groups [9]. Eight studies found a statistically significant positive association between $\mathrm{HCV}$ and ICC (odds ratio $(\mathrm{OR})=2.5$ to 9.7) $[9-14,19,23]$. Four studies did not find a positive association between HCV and ICC $[7,15,17,18]$, whereas two studies did not report the risk estimates [22,24].

\section{$\mathrm{HCV}$ infection and the risk of CCA}

We identified four case-control studies [13,14,20,21] reporting the association between $\mathrm{HCV}$ infection and the risk of CCA. All four studies found a positive 


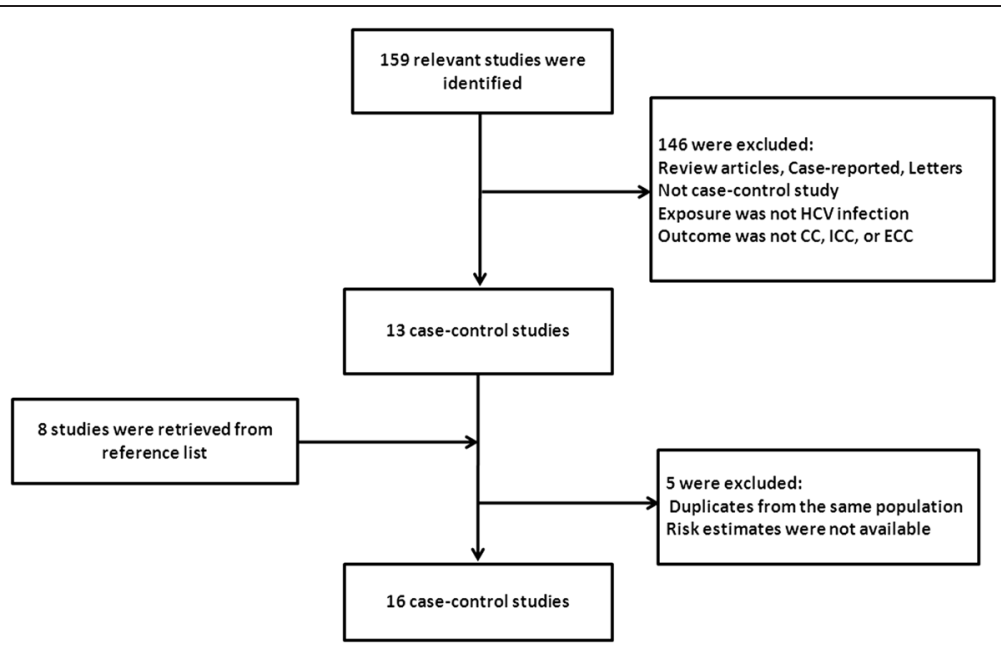

Figure 1 Flow chart of the selection and disposition of studies. A total of 159 relevant studies were identified during the initial search, and 16 studies remained after careful screening.

Table 1 Characteristics of 16 studies of HCV infection and the risk of cholangiocarcinoma

\begin{tabular}{|c|c|c|c|c|c|c|c|c|c|}
\hline \multirow[t]{2}{*}{ Study } & \multirow[t]{2}{*}{ Country } & \multirow{2}{*}{$\begin{array}{l}\text { CCA } \\
\text { type }\end{array}$} & \multicolumn{2}{|c|}{ Demographics } & \multirow{2}{*}{$\begin{array}{l}\text { Case } \\
\text { (n) }\end{array}$} & \multirow{2}{*}{$\begin{array}{l}\text { Control } \\
\text { (n) }\end{array}$} & \multirow[t]{2}{*}{ Sources } & \multirow[t]{2}{*}{ OR $(95 \% \mathrm{Cl})$} & \multirow[t]{2}{*}{ Adjustments } \\
\hline & & & $\begin{array}{l}\text { Age } \\
\text { (Y) }\end{array}$ & $\begin{array}{l}\text { Sex } \\
(\% \mathrm{M})\end{array}$ & & & & & \\
\hline Liu (2011) [7] & China & ICC & $\geqq 50$ & 39 & 87 & 228 & Hospital-based & 0.87 (0.09 to 18.50$)$ & NR \\
\hline Shin (1996) [9] & Korea & ICC & 59 & 73.2 & 41 & 406 & Hospital-based & 6.80 (2.30 to 20.30$)$ & age, sex \\
\hline Donato (20011) [10] & Italy & ICC & 65 & 80.8 & 26 & 824 & Hospital-based & 9.70 (1.60 to 58.90) & sex, age, residence \\
\hline Zhou (2008) [15] & China & ICC & 53.2 & 66 & 312 & 438 & Hospital-based & 0.93 (0.28 to 3.10$)$ & age, sex \\
\hline Shaib (2005) [12] & United States & ICC & 78.7 & 51.7 & 625 & 90,834 & Population-based & 6.10 (4.30 to 8.60$)$ & $\begin{array}{l}\text { age, sex, race, geographic } \\
\text { location, }\end{array}$ \\
\hline \multirow[t]{2}{*}{ Shaib (2007) [13] } & \multirow[t]{2}{*}{ United States } & ICC & 59.8 & 55.4 & 83 & \multirow[t]{2}{*}{236} & \multirow[t]{2}{*}{ Hospital-based } & 7.90 (1.30 to 84.50$)$ & \multirow{2}{*}{$\begin{array}{l}\text { age, ethnicity, anti-HCV, } \\
\mathrm{HbsAg} \text { anti-HBc, } \\
\text { alcohol consumption }\end{array}$} \\
\hline & & ECC & 61.1 & 67.6 & 163 & & & $2.80(0.30$ to 35.10$)$ & \\
\hline $\begin{array}{l}\text { Yamamoto } \\
\text { (2004) [11] }\end{array}$ & Japan & ICC & 64.6 & 58 & 50 & 205 & Hospital-based & $6.02(1.51$ to 24.1$)$ & $\begin{array}{l}\text { aspartate aminotransferase, } \\
\text { blood transfusion, } \\
\text { diabetes mellitus }\end{array}$ \\
\hline \multirow[t]{2}{*}{ Welzel (2007) [14] } & \multirow[t]{2}{*}{ United States } & ICC & 79 & 48 & 535 & \multirow[t]{2}{*}{102,782} & \multirow[t]{2}{*}{ Population-based } & 4.40 (1.40 to 140$)$ & \multirow[t]{2}{*}{ age, race, geographic region } \\
\hline & & ECC & 78.7 & 51 & 549 & & & 1.50 (0.20 to 11.00$)$ & \\
\hline Lee (2008) [17] & South Korea & ICC & 60.7 & 69.1 & 622 & 2,488 & Hospital-based & 1.00 (0.50 to 1.90$)$ & age, sex \\
\hline Hsing (2008) [18] & China & ECC & 67 & 58.2 & 134 & 762 & Population-based & $0.80(0.20$ to 3.40$)$ & $\begin{array}{l}\text { education, smoking, BMI, } \\
\text { diabetes, gallstones }\end{array}$ \\
\hline Tao (2009) [20] & China & ICC & $\geqq 50$ & 60.7 & 61 & 380 & Hospital-based & 6.30 (0.40 to 102.30$)$ & $N R$ \\
\hline Lee (2009) [19] & $\begin{array}{l}\text { Taiwan, Republic } \\
\text { of China }\end{array}$ & ICC & 61.5 & 63.1 & 160 & 160 & Hospital-based & 2.71 (1.16 to 6.32) & NR \\
\hline $\begin{array}{l}\text { Srivatanakul } \\
(2010)[21]\end{array}$ & Thailand & CCA & NR & NR & 103 & 103 & Hospital-based & $7 / 0$ (1.44 to infinity) & anti-OV Ab \\
\hline Welzel (2011) [23] & United States & ICC & 76.4 & 47.5 & 743 & 195,953 & Population-based & 8.05 (5.08 to 12.75$)$ & $\begin{array}{l}\text { age, sex, race, } \\
\text { geographic location }\end{array}$ \\
\hline Cai (2011) [22] & China & ICC & 56.6 & 62.0 & 313 & 608 & Hospital-based & NR & NR \\
\hline Qu (2012) [24] & China & ECC & 63 & 63.9 & 305 & 480 & Hospital-based & NR & NR \\
\hline
\end{tabular}

$\mathrm{M}$, male; $\mathrm{Y}$, year; CCA, cholangiocarcinoma; $\mathrm{ECC}$, extrahepatic cholangiocarcinoma; ICC, intrahepatic cholangiocarcinoma; $\mathrm{Cl}$, confidence interval; OR, odds ratio; $\mathrm{NR}$, not reported; BMI, body mass index; OV, opisthorchis viverrini; $A b$, antibody. 
correlation between $\mathrm{HCV}$ and the risk of CCA (OR = 2.49 to 13.99$)$. In the present study, the meta-analysis of four case-control studies showed an OR of 5.44 (95\% CI, 2.72 to 10.89) (Figure 2). The heterogeneity was not significant $\left(I^{2}=0.0 \%, P=0.704\right)$.

\section{HCV infection and the risk of ICC}

We found a statistically significant positive association between HCV infection and ICC incidence $(\mathrm{OR}=3.38$, 95\% CI, 2.72 to $4.21, P<0.001)$ in a random-effects model in the meta-analysis for 13 case-control studies [7,9-15,17,19,20,22,23], (Figure 3). In this meta-analysis, we found significant heterogeneity among the casecontrol studies $\left(Q=64.32, I^{2}=81.3 \%, P<0.001\right)$. In order to explore potential sources of heterogeneity, we conducted subgroup analyses by geographic region, sources, control groups, and adjusted covariates (Table 2). Among 13 case-control studies, 8 studies were from Asia $[7,9,11,15,17,19,20,22], 4$ from North America [12-14,23], and 1 from Europe [10]. The pooled OR of North American studies (OR $=6.48,95 \% \mathrm{CI}, 4.97$ to 8.46 ) was higher than that of Asian studies (OR $=2.01,95 \% \mathrm{CI}$, 1.44 to 2.79$)$ and the European study $(\mathrm{OR}=4.64,95 \% \mathrm{CI}$, 1.79 to 12.08$)$. The heterogeneity was significant in Asian studies $\left(I^{2}=77.30 \%, P<0.001\right)$, but not in North American studies. The pooled ORs were 2.24 (95\% CI, 1.65 to 3.05) for studies with hospitalized controls and 3.38 (95\% CI, 2.72 to 4.21 ) with population-based controls. The heterogeneity was significant only in studies with hospitalized controls $\left(I^{2}=74.20 \%, P<0.001\right)$.

\section{$\mathrm{HCV}$ infection and the risk of ECC}

Five case-control studies reported results on $\mathrm{HCV}$ and ECC $[13,14,18,20,24]$. Among these studies, three studies $[13,14,20]$ showed a statistically significant positive association between $\mathrm{HCV}$ and ECC (OR $=4.47$ to 9.02), and two studies $[18,24]$ showed no significant positive associations ( $\mathrm{OR}=0.75$ to 0.78 ). In our metaanalysis of these studies, the pooled risk estimate was 1.75 (95\% CI, 1.00 to 3.05 ) in a random-effects model (Figure 4).

In the subgroup analysis (Table 2), three studies were from Asia, and two from North America. The pooled OR of North American studies (OR $=4.88,95 \%$ CI, 1.88 to 12.65$)$ was higher than that of Asian studies (OR = $1.06,95 \% \mathrm{CI}, 0.52$ to 2.19 ). No significant heterogeneity was shown in any of the subgroups. The pooled ORs were 1.66 (95\% CI, 0.81 to 3.41$)$ for studies with hospitalized controls and $1.91(95 \% \mathrm{CI}, 0.81$ to 4.50$)$ with population-based controls. Significant heterogeneity was found between studies with hospitalized controls and studies with population-based controls.

\section{Publication bias}

Funnel plots showed no publication bias in studies concerning CCA, ICC, and ECC (Figure 5). P values for Begg's adjusted rank correlation test and Egger's regression asymmetry test were positive $(P>0.05)$, suggesting that publication bias had little effect on summary estimates.

\section{Discussion}

The global prevalence of CCA has shown a rising trend in recent years, and the incidence of HCV infection is also found to be elevated [2,25-28]. Although many researchers have focused on the association between $\mathrm{HCV}$ infection and the risk of CCA, the findings have varied due to differences between the studies in geographic

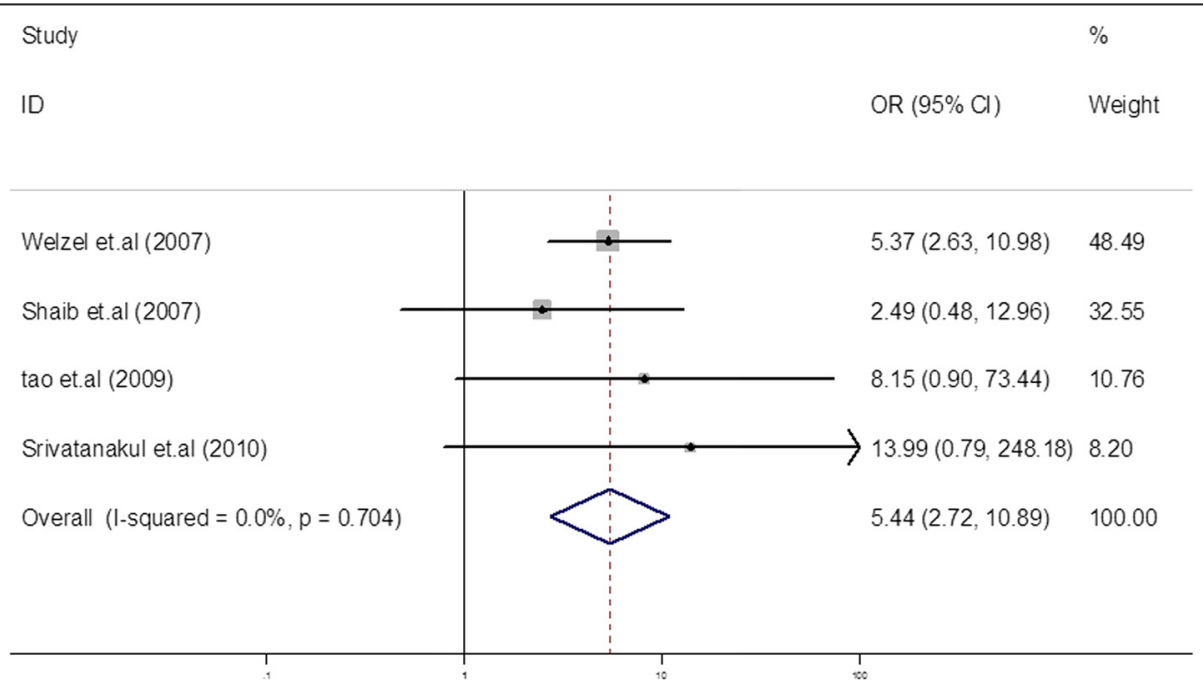

Figure 2 Forest plot of cholangiocarcinoma risk associated with HCV infection. A statistically significant positive association between HCV infection and CCA incidence was found $(\mathrm{OR}=5.44,95 \% \mathrm{Cl}, 2.72$ to 10.89$)$ in a random-effects model in the meta-analysis of four case-control studies. 


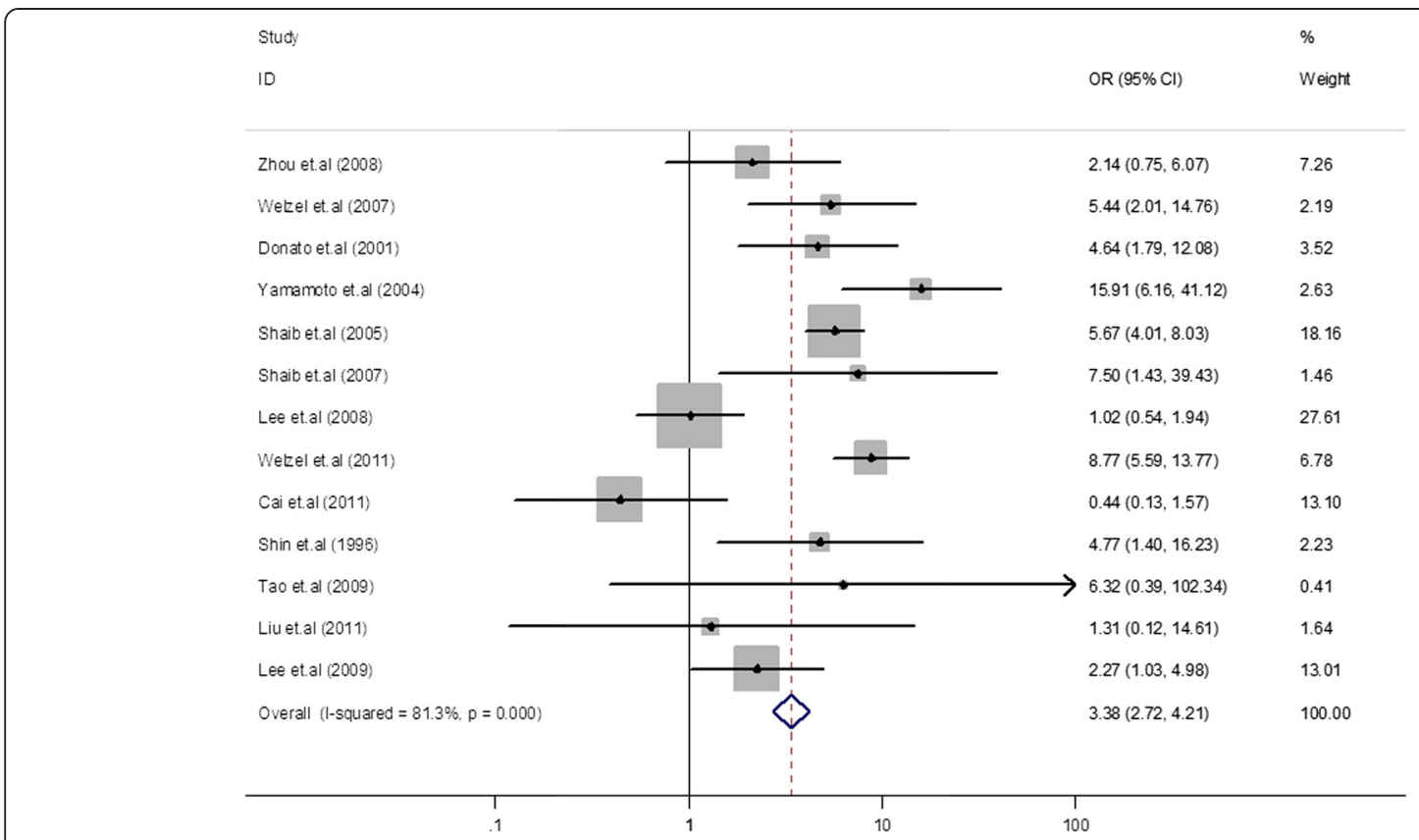

Figure 3 Forest plot of intrahepatic cholangiocarcinoma risk associated with HCV infection. A statistically significant positive association between HCV infection and ICC incidence was found $(\mathrm{OR}=3.38,95 \% \mathrm{Cl}, 2.72$ to $4.21, P<0.001)$ in a random-effects model in the meta-analysis of 13 case-control studies.

regions, study design, sample size, and controls. Also, in previous meta-analyses, adjusted risk estimates were used rather than the unadjusted risk estimates used in the present study. Regarding the potential confounding factors for CCA, summary risk estimates are more precise and believable when using findings from adjusted models. Although previous studies referred to $\mathrm{HCV}$ and CCA, they mainly focused on HBV rather than HCV, and ICC rather than ECC or CCA [29,30]. Further, just as different anatomic locations of CCA have distinct epidemiologic features and different risk factors [13], ICC and ECC also have many differences. The present study

Table 2 Summary of risk estimates and $95 \% \mathrm{Cl}$ for the case-control studies

\begin{tabular}{|c|c|c|c|c|c|}
\hline \multirow[t]{2}{*}{ Study } & \multirow{2}{*}{$\begin{array}{l}\text { Number of } \\
\text { studies }\end{array}$} & \multirow[t]{2}{*}{ OR $(95 \% \mathrm{Cl})$} & \multicolumn{3}{|c|}{ Tests for heterogeneity } \\
\hline & & & $\bar{Q}$ & $P$ value & $I^{2}(\%)$ \\
\hline ICC & 13 & & & & \\
\hline \multicolumn{6}{|l|}{ Control group } \\
\hline Hospital-based & 10 & 2.24 (1.65 to 3.05$)$ & 34.93 & $<0.001$ & 74.20 \\
\hline Population-based & 3 & 3.38 (2.72 to 4.21$)$ & 2.43 & 0.297 & 17.60 \\
\hline \multicolumn{6}{|l|}{ Geographic region } \\
\hline North America & 4 & 6.48 (4.97 to 8.46$)$ & 2.44 & 0.486 & 0 \\
\hline Asia & 8 & 2.01 (1.44 to 2.79$)$ & 30.83 & $<0.001$ & 77.30 \\
\hline Europe & 1 & 4.64 (1.79 to 12.08$)$ & 0 & & 0 \\
\hline ECC & 5 & & & & \\
\hline \multicolumn{6}{|l|}{ Control group } \\
\hline Hospital-based & 3 & $1.66(0.81$ to 3.41$)$ & 5.80 & 0.055 & 65.50 \\
\hline Population-based & 2 & 1.91 (0.81 to 4.50$)$ & 5.54 & 0.019 & 81.90 \\
\hline \multicolumn{6}{|l|}{ Geographic region } \\
\hline North America & 2 & 4.88 (1.88 to 12.65$)$ & 0.04 & 0.845 & 0 \\
\hline Asia & 3 & $1.06(0.52$ to 2.19$)$ & 3.98 & 0.137 & $49.7 \%$ \\
\hline
\end{tabular}

$\mathrm{OR}$, odds ratio; $\mathrm{Cl}$, confidence interval; $\mathrm{ECC}$, extrahepatic cholangiocarcinoma; ICC, intrahepatic cholangiocarcinoma. 


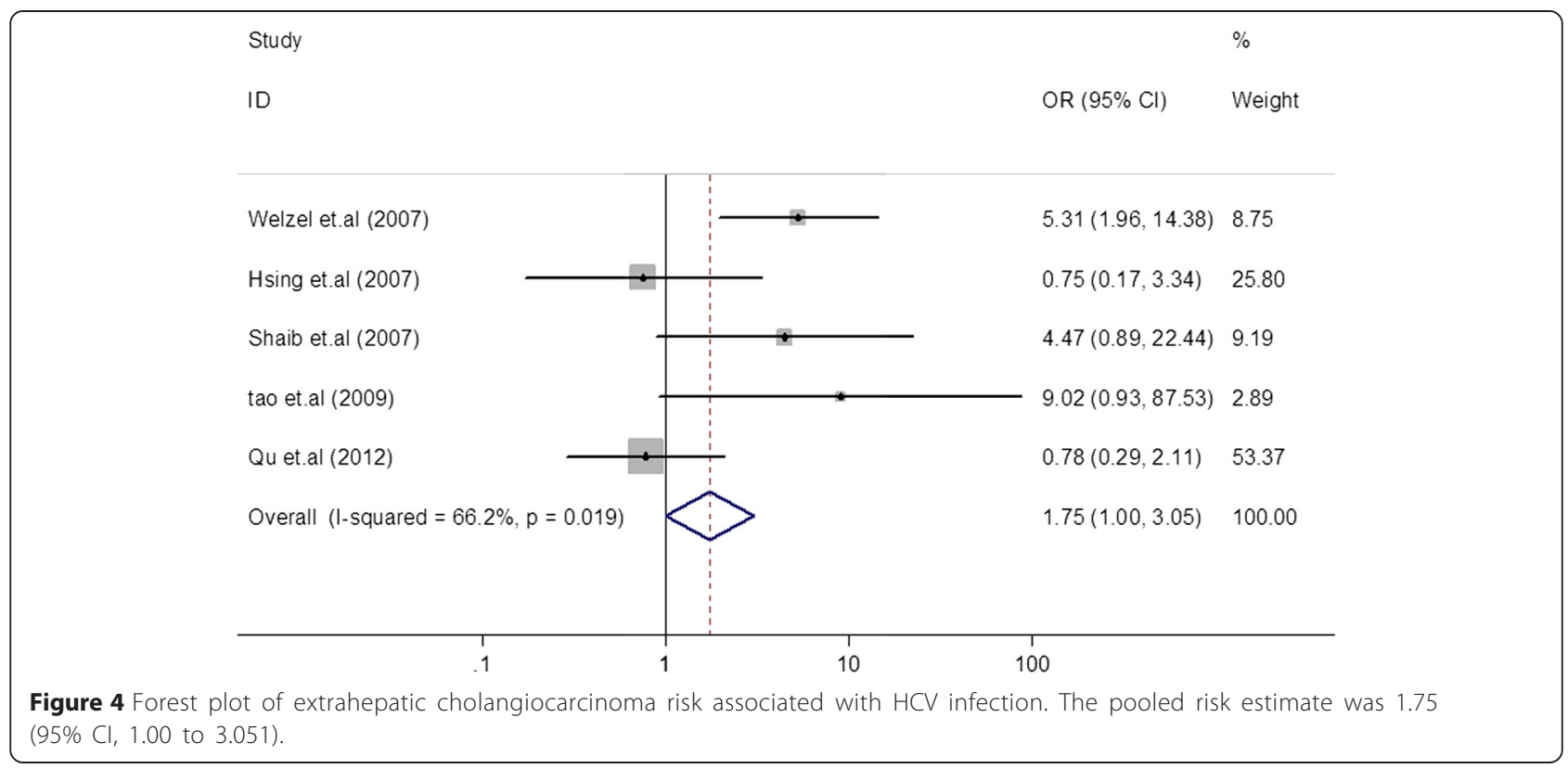

has compensated for these deficiencies by focusing on $\mathrm{HCV}$ and CCA, including ICC and ECC. Moreover, the 16 case-control studies included in our meta-analysis exceed the number of studies included in previous metaanalysis. Therefore, results and conclusions of our data analysis are more reliable than previously published meta-analyses. The present meta-analysis was conducted to evaluate the relationship between $\mathrm{HCV}$ infection and the risk of ICC, ECC, and CCA and was not confined to associations between HCV and ICC.

The present study found that patients with an $\mathrm{HCV}$ infection have an approximately 5.44-fold increased risk of CCA compared to individuals with a non-HCV infection. In the study by Srivatanakul et al. [21], the OR for CCA was 4.00. These results indicate that HCV is associated with CCA incidence. To gain insight into the association between $\mathrm{HCV}$ and CCA, we classified CCA into ICC and ECC. The pooled OR of ICC $(\mathrm{OR}=3.38$, 95\% CI, 2.72 to 4.21) was higher than that of ECC $(\mathrm{OR}=1.75,95 \% \mathrm{CI}, 1.00$ to 3.05$)$. This can probably be explained by the different anatomic locations of CCA, which were associated with different risk factors for CCA. From these results, we concluded that ICC was probably more susceptible to HCV infection than ECC. In subgroup analysis of HCV and the risk of ICC in different geographic regions, the pooled OR was obviously higher in studies from North America than those from Asia (6.48 versus 2.01$)$. This phenomenon was also seen in the subgroup analysis of HCV and the risk of ECC (4.88 versus 1.06$)$ in the different geographic regions. This might be explained by the fact that hepatitis $C$ was the most prevalent form of viral hepatitis infection in Western countries compared to Asian countries. As many studies have reported, ICC incidence is rising in

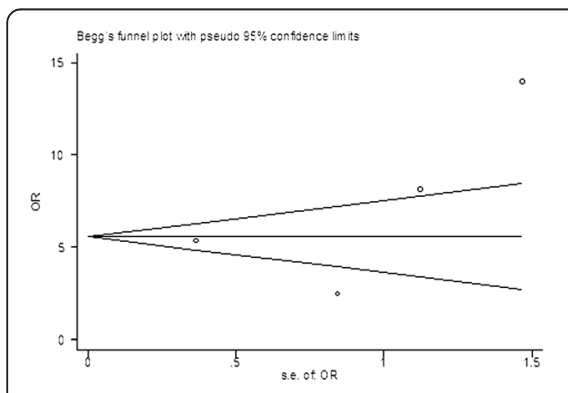

a

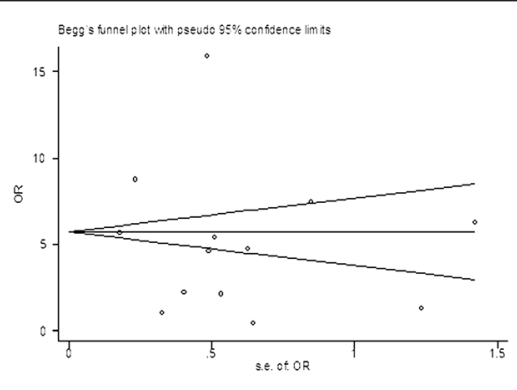

b

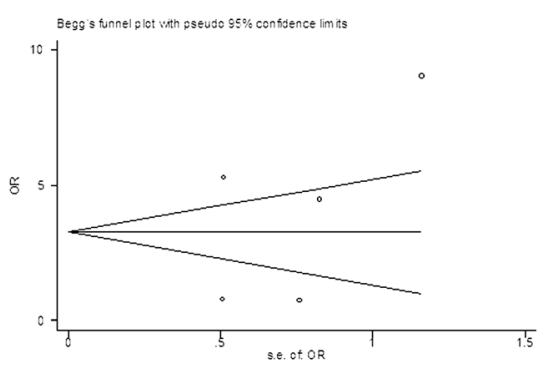

C

Figure 5 Funnel plot of four studies. (a) No publication bias was found between HCV infection and CCA risk using Begg's adjusted rank correlation test $(P=0.308)$ and Egger's regression asymmetry test $(P=0.485)$. Funnel plot of 13 studies; (b) no publication bias was found between HCV infection and ICC risk using Begg's adjusted rank correlation test $(P=0.951)$ and Egger's regression asymmetry test $(P=0.606)$. Funnel plot of 5 studies; (c) no publication bias was found between HCV infection and ECC risk using Begg's adjusted rank correlation test $(P=0.221)$ and Egger's regression asymmetry test $(P=0.495)$. 
Western countries, which may reflect that regional differences have led to different risk factors and epidemiological factors associated with ICC [2,29,31,32]. In subgroup analyses of controls, studies using hospitalbased controls and those using population-based controls had similar risk estimates for ICC (2.24 versus 3.38 ) and ECC (1.66 versus 1.91).

The mechanism of CCA development in patients with $\mathrm{HCV}$ infection has not yet been clarified in detail. One study suggests that the presence of $\mathrm{HCV}$ in the bile duct epithelium indicates that $\mathrm{HCV}$ infection can cause chronic inflammation of the bile duct epithelium [33]. Long-term expression of $\mathrm{HCV}$ oncoproteins may be involved in the tumourigenic process leading to tumor formation [34]. Another study reported that HCV core variants could alleviate TGF-beta cytostatic responses and increase TGF-beta-mediated epithelial-to-mesenchymal transition (EMT), thereby promoting cell invasion and metastasis [35]. Likewise, Chen et al. [36] found that HCV core protein promoted the cellular proliferation of hilar cholangiocarcinoma cells and inhibited apoptosis. Clearly, based on such results, HCV can lead to hepatocellular carcinoma (HCC). Moreover, some researchers have suggested that hepatocytes and cholangiocytes have the same progenitor cells, which are hepatic progenitor cells, especially in ICC and HCC [37]. Therefore, it is possible that $\mathrm{HCV}$ induces carcinogenesis in cholangiocytes and hepatocytes by the same mechanism. Recently, HCV RNA has been detected in ICC specimens, which further indicates the potential role of $\mathrm{HCV}$ infection in the pathogenesis of ICC $[36,38,39]$. Since HCV RNA or its components can be detected in bile duct epithelium [40,41], our results demonstrate a slight positive association between HCV infection and ECC. HCV infection can increase the risk of ECC by $1.75 \%$. This conclusion is consistent with studies by both Welzel et al. [12] and Shaib et al. [14]. However, $\mathrm{Qu}$ et al. [24] found that the seroprevalence of anti-HCV was $4.3 \%$ in ECC patients and $5.6 \%$ in patients with benign biliary disease but without significant differences. HCV infection has been shown to be associated with ICC and its increasing incidence, but not with ECC or its incidence [14]. Similarly, Matsumoto et al. [42] also found that HCV-Ab was $20 \%$ in ICC patients and 7.4\% in ECC patients [42]. Results of both of these studies explain that $\mathrm{HCV}$ is the major risk factor for ICC but not for ECC.

This meta-analysis has several limitations that should be considered when interpreting the results. First, conducting randomized clinical trials was not feasible for an observational study of $\mathrm{HCV}$ and the risk of CCA. All studies included in this meta-analysis were case-control studies that might introduce selection and recall biases, which may possibly distort the true associations between $\mathrm{HCV}$ and CCA. Second, seropositivity for anti-HCV was used as the sole marker of $\mathrm{HCV}$ infection, and the definition of HCV infection was not stated in most studies, therefore a common definition may be lacking. Occult HCV infection might also play a role in the development of CCA. Thus, for these reasons, the HCV effect may be underestimated. Third, the diagnostic misclassification of cholangiocarcinoma (that is, hilar cholangiocarcinoma classification as intrahepatic or extrahepatic tumors) might result in a mismatch of true ICC or ECC.

\section{Conclusions}

The results of the present study reveal that $\mathrm{HCV}$ is associated with the significantly increasing risk of CCA, including ICC and ECC, especially ICC. Further studies are warranted to gain a better understanding of the precise mechanism between HCV and CCA.

\section{Abbreviations \\ HCV: hepatitis C virus; CCA: cholangiocarcinoma; ICC: intrahepatic cholangiocarcinoma; ECC: extrahepatic cholangiocarcinoma; Cl: confidence interval; OR: odds ratio.}

\section{Competing interests}

The authors declare that they have no competing interests.

\section{Authors' contributions}

ZGW and ZZY participated in the design of the study. LH and HB searched the databases and performed the statistical analysis. ZZQ and GJ helped to draft the manuscript. All authors read and approved the final manuscript.

\section{Acknowledgements}

We are very grateful to the authors of the primary studies included in our meta-analysis; their contributions allowed this work to be carried out successfully. We are very grateful to Professor Ding, who helped to perform the statistical analysis. This study was supported by the Natural Science Foundation of China (NSFC 81170721).

\section{Author details}

${ }^{1}$ Department of Surgery, Medical Center of Digestive Disease, Shanghai Jiao Tong University Affiliated First People's Hospital, No. 100, Haining Road, 200080 Shanghai, China. ${ }^{2}$ Department of Surgery, Shanghai Jiao Tong University Affiliated Sixth People's Hospital, No. 600, Yishan Road, 200233 Shanghai, China.

Received: 4 December 2014 Accepted: 14 April 2015

Published online: 23 April 2015

\section{References}

1. Patel T. Cholangiocarcinoma. Nat Clin Pract Gastroenterol Hepatol. 2006;3:33-42.

2. Sripa B, Pairojkul C. Cholangiocarcinoma: lessons from Thailand. Curr Opin Gastroenterol. 2008;24:349-56.

3. Gatto M, Bragazzi MC, Semeraro R, Napoli C, Gentile R, Torrice A, et al. Cholangiocarcinoma: update and future perspectives. Dig Liver Dis. 2010;42:253-60.

4. Patel T. Worldwide trends in mortality from biliary tract malignancies. BMC Cancer. 2002;2:10.

5. Broome U, Lofberg R, Veress B, Eriksson LS. Primary sclerosing cholangitis and ulcerative colitis: evidence for increased neoplastic potential. Hepatology. 1995;22:1404-8.

6. Watanapa P, Watanapa WB. Liver fluke-associated cholangiocarcinoma. Br J Surg. 2002:89:962-70.

7. Liu ZY, Zhou YM, Shi LH, Yin ZF. Risk factors of intrahepatic cholangiocarcinoma in patients with hepatolithiasis: a case-control study. Hepatobiliary Pancreat Dis Int. 2011;10:626-31. 
8. Tyson GL, El-Serag HB. Risk factors for cholangiocarcinoma. Hepatology. 2011;54:173-84.

9. Shin HR, Lee CU, Park HJ, Seol SY, Chung JM, Choi HC, et al. Hepatitis B and $C$ virus, Clonorchis sinensis for the risk of liver cancer: a case-control study in Pusan, Korea. Int J Epidemiol. 1996;25:933-40.

10. Donato F, Gelatti U, Tagger A, Favret M, Ribero ML, Callea F, et al. Intrahepatic cholangiocarcinoma and hepatitis $\mathrm{C}$ and $\mathrm{B}$ virus infection, alcohol intake, and hepatolithiasis: a case-control study in Italy. Cancer Causes Control. 2001;12:959-64.

11. Yamamoto $S$, Kubo $S$, Hai $S$, Uenishi $T$, Yamamoto T, Shuto T, et al. Hepatitis C virus infection as a likely etiology of intrahepatic cholangiocarcinoma. Cancer Sci. 2004;95:592-5.

12. Shaib YH, El-Serag HB, Davila JA, Morgan R, McGlynn KA. Risk factors of intrahepatic cholangiocarcinoma in the United States: a case-control study. Gastroenterology. 2005;128:620-6.

13. Shaib YH, El-Serag HB, Nooka AK, Thomas M, Brown TD, Patt YZ, et al. Risk factors for intrahepatic and extrahepatic cholangiocarcinoma: a hospital-based case-control study. Am J Gastroenterol. 2007;102:1016-21.

14. Welzel TM, Graubard Bl, El-Serag HB, Shaib YH, Hsing AW, Davila JA, et al. Risk factors for intrahepatic and extrahepatic cholangiocarcinoma in the United States: a population-based case-control study. Clin Gastroenterol Hepatolo. 2007;5:1221-8.

15. Zhou YM, Yin ZF, Yang JM, Li B, Shao WY, Xu F, et al. Risk factors for intrahepatic cholangiocarcinoma: a case-control study in China. World J Gastroenterol. 2008;14:632-5.

16. Begg CB, Mazumdar M. Operating characteristics of a rank correlation test for publication bias. Biometrics. 1994;50:1088-101.

17. Lee TY, Lee SS, Jung SW, Jeon SH, Yun SC, Oh HC, et al. Hepatitis B virus infection and intrahepatic cholangiocarcinoma in Korea: a case-control study. Am J Gastroenterol. 2008;103:1716-20.

18. Hsing AW, Zhang M, Rashid A, McGlynn KA, Wang BS, Niwa S, et al. Hepatitis $B$ and $C$ virus infection and the risk of biliary tract cancer: a population-based study in China. Int J Cancer. 2008;122:1849-53.

19. Lee CH, Chang CJ, Lin YJ, Yeh CN, Chen MF, Hsieh SY. Viral hepatitis-associated intrahepatic cholangiocarcinoma shares common disease processes with hepatocellular carcinoma. Br J Cancer. 2009;100:1765-70.

20. Tao LY, He XD, Cai L, Liu W, Ji WJ, Zhao L, et al. Case-control study of risk factors in cholangiocarcinoma. Zhonghua zhong liu za zhi. 2009;31:759-63.

21. Srivatanakul P, Honjo S, Kittiwatanachot P, Jedpiyawongse A, Khuhaprema T, Miwa M. Hepatitis viruses and risk of cholangiocarcinoma in northeast Thailand. Asian Pac J Cancer Prev. 2010;11:985-8.

22. Cai WK, Sima H, Chen BD, Yang GS. Risk factors for hilar cholangiocarcinoma: a case-control study in China. World J Gastroenterol. 2011;17:249-53.

23. Welzel TM, Graubard BI, Zeuzem S, El-Serag HB, Davila JA, McGlynn KA. Metabolic syndrome increases the risk of primary liver cancer in the United States: a study in the SEER-Medicare database. Hepatology. 2011;54:463-71.

24. Qu Z, Cui N, Qin M, Wu X. Epidemiological survey of biomarkers of hepatitis virus in patients with extrahepatic cholangiocarcinomas. Asia Pac J Clin Oncol. 2012;8:83-7.

25. Mouzas IA, Dimoulios P. Vlachonikolis IG, Skordilis P, Zoras O, Kouroumalis E. Increasing incidence of cholangiocarcinoma in Crete 1992-2000. Anticancer Res. 2002;22:3637-41.

26. Okuda K, Nakanuma Y, Miyazaki M. Cholangiocarcinoma: recent progress. Part 1: epidemiology and etiology. J Gastroenterol Hepatol. 2002;17:1049-55.

27. Shaib YH, Davila JA, McGlynn K, El-Serag HB. Rising incidence of intrahepatic cholangiocarcinoma in the United States: a true increase? J Hepatol. 2004:40:472-7.

28. Khan SA, Toledano MB, Taylor-Robinson SD. Epidemiology, risk factors, and pathogenesis of cholangiocarcinoma. HPB(Oxford). 2008;10:77-82.

29. Patel T. Increasing incidence and mortality of primary intrahepatic cholangiocarcinoma in the United States. Hepatology. 2001;33:1353-7.

30. Zhou Y, Zhao Y, Li B, Huang J, Wu L, Xu D, et al. Hepatitis viruses infection and risk of intrahepatic cholangiocarcinoma: evidence from a meta-analysis. BMC Cancer. 2012;12:289.

31. McGlynn KA, Tarone RE, El-Serag HB. A comparison of trends in the incidence of hepatocellular carcinoma and intrahepatic cholangiocarcinoma in the United States. Cancer Epidemiol Biomarkers Prev. 2008;15:1198-203.

32. West J, Wood H, Logan RF, Quinn M, Aithal GP. Trends in the incidence of primary liver and biliary tract cancers in England and Wales 1971-2001. Br J Cancer. 2006;94:1751-8.
33. Fillipowicz EA, Xiao S, Sower LE, Weems J, Payne DA. Detection of HCV in bile duct epithelium by laser capture microdissection (LCM). In Vivo. 2005;19:737-9.

34. Einav S, Sklan EH, Moon HM, Gehrig E, Liu P, Hao Y, et al. The nucleotide binding motif of hepatitis C virus NS4B can mediate cellular transformation and tumor formation without Ha-ras co-transfection. Hepatology. 2008:47:827-35.

35. Battaglia S, Benzoubir N, Nobilet S, Charneau P, Samuel D, Zignego AL, et al. Liver cancer-derived hepatitis C virus core proteins shift TGF-beta responses from tumor suppression to epithelial-mesenchymal transition. PloS One. 2009;: :e4355.

36. Chen RF, Li ZH, Zou SQ, Chen JS. Effect of hepatitis C virus core protein on modulation of cellular proliferation and apoptosis in hilar cholangiocarcinoma. Hepatobiliary Pancreat Dis Int. 2005;4:71-4.

37. Roskams T. Liver stem cells and their implication in hepatocellular and cholangiocarcinoma. Oncogene. 2006;25:3818-22.

38. Perumal V, Wang J, Thuluvath P, Choti M, Torbenson M. Hepatitis C and hepatitis $B$ nucleic acids are present in intrahepatic cholangiocarcinomas from the United States. Hum Pathol. 2006;37:1211-6.

39. Torbenson M, Yeh MM, Abraham SC. Bile duct dysplasia in the setting of chronic hepatitis C and alcohol cirrhosis. Am J Surg Pathol. 2007:31:1410-3.

40. Lu H, Ye MQ, Thung SN, Dash S, Gerber MA. Detection of hepatitis $C$ virus RNA sequences in cholangiocarcinomas in Chinese and American patients. Chin Med J (Engl). 2000;113:1138-41.

41. Liu XF, Zou SQ, Qiu FZ. Pathogenesis of cholangiocarcinoma in the porta hepatis and infection of hepatitis virus. Hepatobiliary Pancreat Dis Int. 2003;2:285-9.

42. Matsumoto K, Onoyama T, Kawata S, Takeda Y, Harada K, Ikebuchi Y, et al. Hepatitis $B$ and $C$ virus infection is a risk factor for the development of cholangiocarcinoma. Intern Med. 2014;53:651-4.

\section{Submit your next manuscript to BioMed Central and take full advantage of:}

- Convenient online submission

- Thorough peer review

- No space constraints or color figure charges

- Immediate publication on acceptance

- Inclusion in PubMed, CAS, Scopus and Google Scholar

- Research which is freely available for redistribution 